\title{
De novo Crohn's Disease Following Orthotopic Liver Transplantation: A Case Report and Literature Review
}

\author{
Takeo Naito ${ }^{1}$, Hisashi Shiga ${ }^{1}$, Katsuya Endo ${ }^{1}$, Masatake Kuroha ${ }^{1}$, Yoichi Kakuta ${ }^{1}$, \\ Yoshitaka Kinouchi ${ }^{2}$ and Tooru Shimosegawa ${ }^{1}$
}

\begin{abstract}
The development of de novo Crohn's disease (CD) after orthotopic liver transplantation (OLT) is rare, possibly due to the continuous use of immunosuppressive treatment. Although several cases of CD following OLT have been reported worldwide, there are currently so such cases in Japan. We herein report the case of a patient who newly developed CD after undergoing OLT for congenital biliary atresia. The patient subsequently underwent ileocecal resection and has since maintained clinical remission. This is the first report of this condition in Japan. We also review the literature concerning cases of de novo inflammatory bowel disease (IBD) developing after OLT, and discuss the causes of and role of immunosuppressive agents in treating IBD.
\end{abstract}

Key words: Crohn's disease, de novo Crohn's disease, orthotopic liver transplantation, immunosuppressive agents

(Intern Med 54: 199-204, 2015)

(DOI: 10.2169/internalmedicine.54.3156)

\section{Introduction}

Inflammatory bowel disease (IBD) is a T-cell driven form of inflammation in the gut that is thought to be the result of the inappropriate and ongoing activation of the mucosal immune system $(1,2)$. Therefore, treatment regimens for IBD include immunosuppressive agents, and the immunosuppressive drugs used to manage moderate to severe IBD, such as cyclosporine, azathioprine and corticosteroids, are also employed in the management of post-transplant patients. Nevertheless, 69 cases of de novo ulcerative colitis (UC) have been reported to have developed after orthotopic liver transplantation (OLT), regardless of the use of immunosuppressive agents (Table). A total of $0.25 \%$ of UC patients have accompanying primary sclerosing cholangitis (PSC), and 55$70 \%$ of PSC patients also have UC $(3,4)$. The relationship between UC and PSC may be associated with the development of UC after OLT. However, there have been very few reports of the development of de novo Crohn's disease (CD) after OLT (5-8). In this article, we report the case of a pa- tient who newly developed CD (de novo) after undergoing OLT for congenital biliary atresia. We also review the literature of de novo IBD following OLT and discuss both the causes of this type of IBD and the role of immunosuppressive agents in treating IBD patients.

\section{Case Report}

A 23-year-old Japanese woman experienced repeated episodes of diarrhea and fever in June 2011. She had no past history of IBD, although she had received a liver transplant from her mother for congenital biliary atresia in 2003. After undergoing OLT, she had received treatment with cyclosporine at a dose of $100 \mathrm{mg} / \mathrm{day}$. Although cytomegalovirus (CMV) antigenemia became positive one month after the OLT procedure, the patient exhibited no symptoms, and the antigenemia turned negative within one week without any specific treatment. No other major complications occurred; however, she was admitted to our hospital and diagnosed with acute enterocolitis in June 2011. Her symptoms subsequently improved with the administration of antibiotics, al-

${ }^{1}$ Division of Gastroenterology, Tohoku University Graduate School of Medicine, Japan and ${ }^{2}$ Health Administration Center, Center for the Advancement of Higher Education, Tohoku University, Japan

Received for publication April 24, 2014; Accepted for publication July 31, 2014

Correspondence to Dr. Takeo Naito, takeo.naito24@gmail.com 
Table. Development of De novo IBD after Orthotopic Liver Transplantation in the Literature

\begin{tabular}{|c|c|c|c|c|c|c|c|c|}
\hline Reference & $\begin{array}{l}\text { Underlying cause of } \\
\text { liver transplant }\end{array}$ & $\begin{array}{l}\text { No. of de } \\
\text { novo IBD } \\
\text { patients }\end{array}$ & $\begin{array}{l}\text { No. of de } \\
\text { novo UC } \\
\text { patients }\end{array}$ & $\begin{array}{l}\text { No. of de } \\
\text { novo CD } \\
\text { patients }\end{array}$ & Other & $\begin{array}{l}\text { Treatment } \\
\text { for de } \\
\text { novo IBD }\end{array}$ & $\begin{array}{l}\text { No. of } \\
\text { patients } \\
\text { who } \\
\text { achieved } \\
\text { remission }\end{array}$ & $\begin{array}{l}\text { No. of } \\
\text { patients } \\
\text { who } \\
\text { failed } \\
\text { remission }\end{array}$ \\
\hline 3 & 3/PSC & 3 & 3 & & & $\mathrm{CS}$ & 2 & 1 \\
\hline 5 & 2/PSC,4AIH,8/Others & 14 & 9 & 5 & & 5ASA,CS & 7 & 7 \\
\hline 6 & 2/HCV,1/AIH,1/ALD & 4 & 3 & 1 & & $\mathrm{CS}$ & NA & NA \\
\hline 7 & 3/PSC,3/AIH & 6 & 3 & 1 & 2(IC) & 5ASA,CS & 6 & \\
\hline 8 & 1/PBC, $1 / \mathrm{HBV}$ & 2 & & 2 & & 5ASA,CS & 2 & \\
\hline 9 & $3 \mathrm{PSC} / 5 \mathrm{AIH}$ & 8 & 7 & & $1(\mathrm{IC})$ & $\begin{array}{l}\text { 5ASA,CS, } \\
\text { AZA }\end{array}$ & 6 & 2 \\
\hline 13 & 1/AIH,1/PSC,1/PBC & 3 & 2 & 1 & & 5ASA,CS & 3 & \\
\hline 29 & $\begin{array}{l}\text { 2/AIH,1/Wilson } \\
\text { 1/HBV,1/cryptogenic }\end{array}$ & 5 & 5 & & & 5ASA,CS & 5 & \\
\hline 30 & 3/PSC & 3 & 3 & & & NA & NA & NA \\
\hline 31 & 1/HBV & 1 & 1 & & & NA & NA & NA \\
\hline 32 & 1/PSC & 1 & 1 & & & 5ASA,CS & 1 & \\
\hline 33 & 2/PSC & 2 & 2 & & & NA & NA & NA \\
\hline 34 & 1/PSC,2/AIH & 3 & 3 & & & 5ASA,CS & 3 & \\
\hline 35 & 2/PSC & 2 & 2 & & & NA & NA & NA \\
\hline 36 & 2/AIH & 2 & 2 & & & $\mathrm{CS}$ & NA & NA \\
\hline 37 & 1/PSC & 1 & 1 & & & NA & NA & NA \\
\hline 38 & $1 / \mathrm{HCV}$ & 1 & & 1 & & NS & NA & NA \\
\hline 39 & 1/PSC & 1 & 1 & & & $\mathrm{CS}$ & NA & NA \\
\hline 40 & 5/PSC & 5 & & & NA & NA & NA & NA \\
\hline 41 & 3/PSC & 3 & 3 & & & NA & 2 & 1 \\
\hline 42 & 1/criptogenic LC & 1 & 1 & & & CS,5ASA & 1 & \\
\hline 43 & 1/fluminant hepatitis & 1 & 1 & & & $5 \mathrm{ASA}$ & 1 & \\
\hline 44 & PSC & 11 & 10 & 1 & & NA & NA & NA \\
\hline 45 & 1/PSC,1/AIH,1/BA & 3 & & 2 & $1(\mathrm{IC})$ & $3 \mathrm{IFX}, 1 \mathrm{AD}$ & A 2 & 1 \\
\hline 46 & 6/PSC & 6 & 6 & & & 5ASA,CS,A & AZA 6 & \\
\hline total & & 92 & 69 & 14 & 9 & & 47 & 12 \\
\hline
\end{tabular}

PSC: primary sclerosing cholangitis, AIH: autoimmune hepatitis, HBV: hepatitis B virus, HCV: hepatitis C virus, Wilson: Wilson's disease, ALD: alcoholic liver disease, BA: biliary atresia, IC: indeterminate colitis, NA: not available, CS: corticosteroid, 5ASA: 5 aminosalicylic acid, AZA: azathioprine, IFX: infliximab, ADA: adalimuma

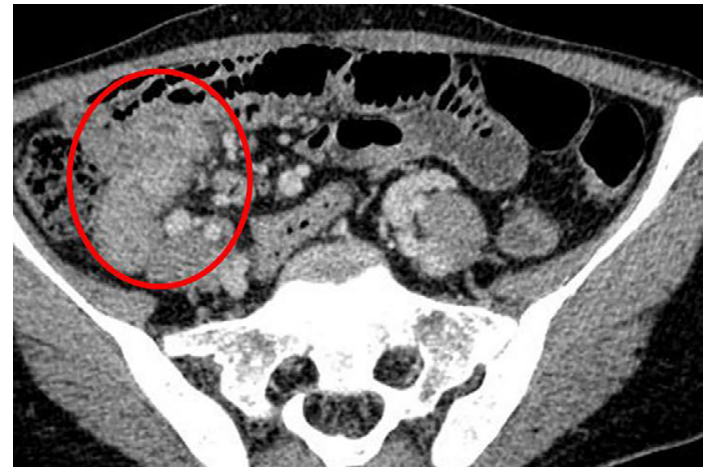

Figure 1. Computed tomography demonstrated wall thickening in the ileum and an increased density of circumintestinal fat tissue (circle).

though, at the end of November, she again developed diarrhea and fever and was readmitted to our hospital in December.

No pathogenic bacteria, such as Salmonella, Shigella, Yersinia, Campylobacter, etc., were detected in a stool culture, and Clostridium difficile toxin A and B were not detected in stool samples. However, computed tomography revealed wall thickening in the ileum and an increase in the density of the circumintestinal fat tissue (Fig. 1). Small

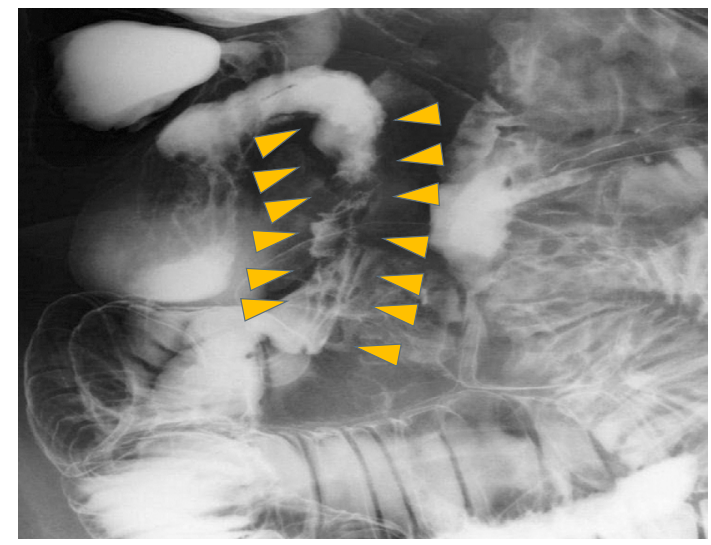

Figure 2. Small bowel follow-through showed mucosal irregularities and narrowing of the terminal ileum (arrowheads).

bowel follow-through (SBFT) showed mucosal irregularities and narrowing of the terminal ileum (Fig. 2). Although, there were no findings in the colon on colonoscopy, except for several small polyps, both ulcers and mucosal edema were noted in the terminal ileum (Fig. 3). Meanwhile, histopathology of the biopsy specimens disclosed mucosal inflammation and non-caseating granuloma, with no malignant findings, and the possibility of CMV infection was excluded histopathologically and serologically using an immunohisto- 

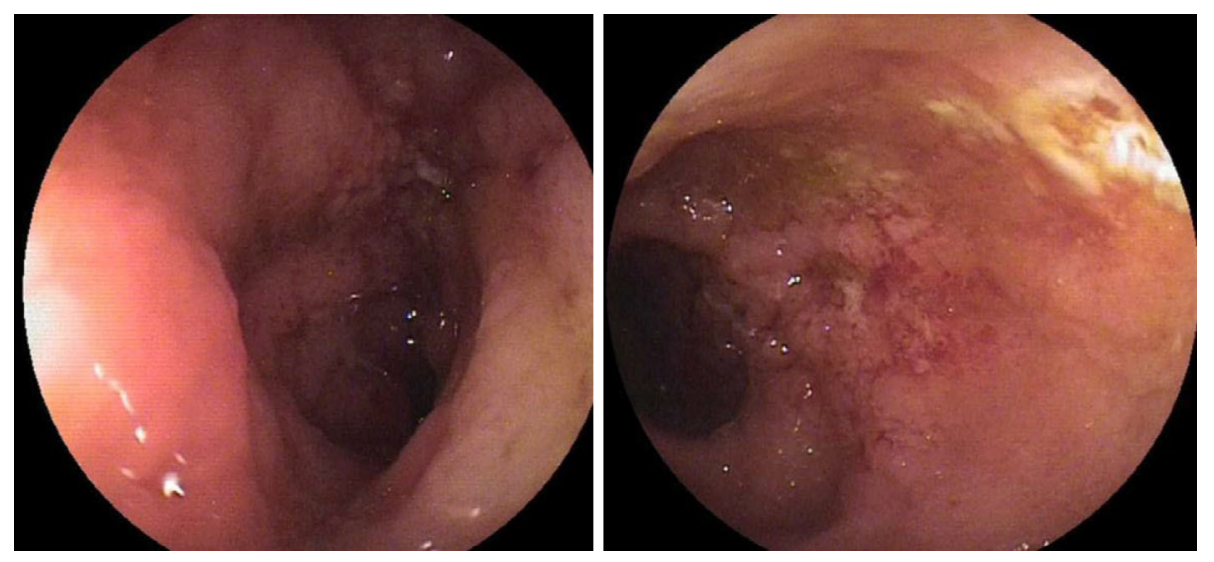

Figure 3. Colonoscopy performed in December 2011 revealed ulcers and mucosal edema in the terminal ileum.
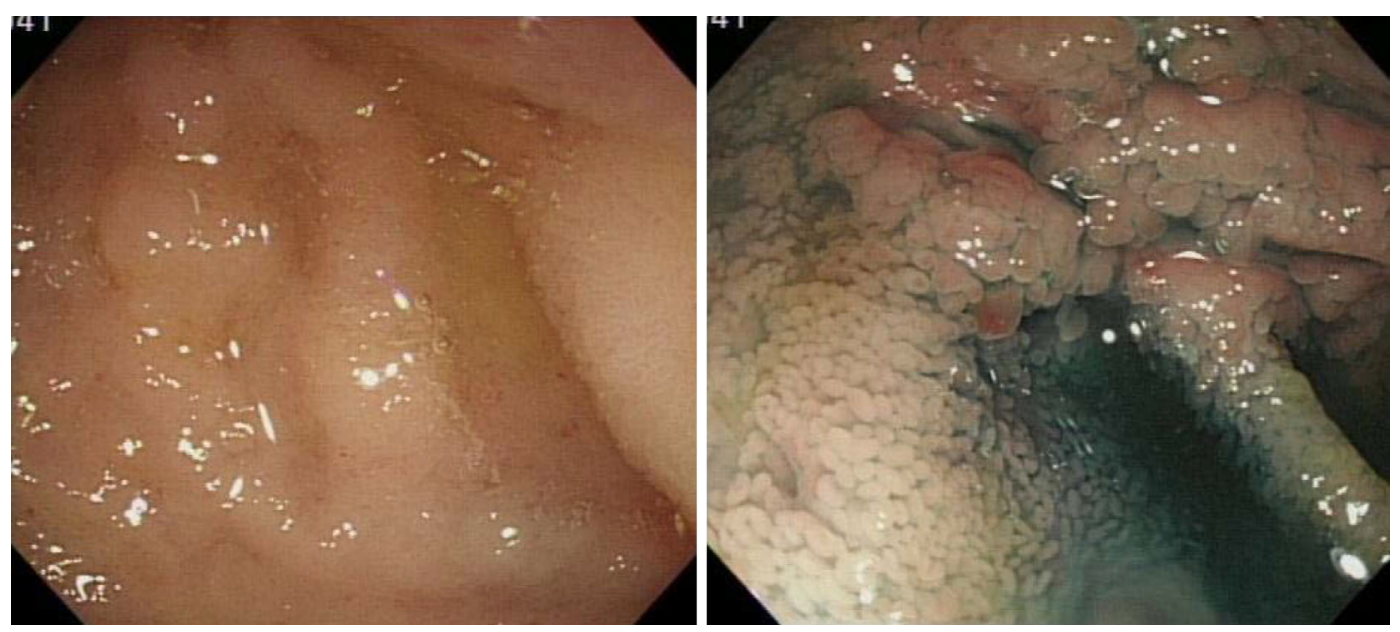

Figure 4. Colonoscopy performed in September 2012 showed ulcers and mucosal edema in the terminal ileum. The oral side of the lesions could not be visualized due to the crooked shape of the intestinal tract.

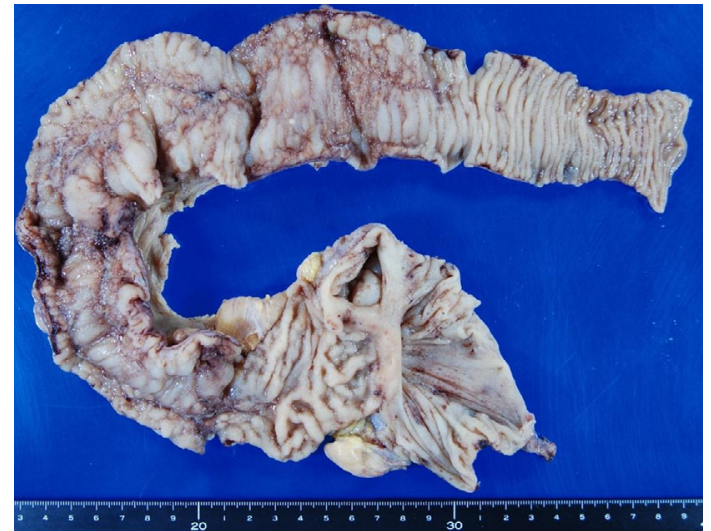

Figure 5. The resected specimen exhibited longitudinal ulcers and a cobblestone appearance. A diagnosis of Crohn's disease was made based on these findings.

chemical analysis and the CMV antigenemia method, respectively. Since the differential diagnoses of infectious enterocolitis and lymphoproliferative diseases were also excluded, the patient was suspected to have $\mathrm{CD}$ and given
2,250 mg/day of 5-aminosalicylic acid (5-ASA). Her condition was stable after discharge; however, she again developed diarrhea and fever in August 2012 and was readmitted to our hospital in late September.

Consequently, colonoscopy showed ulcers and mucosal edema in the terminal ileum (Fig. 4), and SBFT revealed narrowing of the terminal ileum. In contrast, upper gastrointestinal endoscopy showed none of the characteristic features frequently observed in $\mathrm{CD}$ patients, such as a bamboo jointlike appearance. Based on these findings, the patient underwent ileocecal resection in October. The resected specimen was found to have longitudinal ulcers and a cobblestone-like appearance (Fig. 5), and the histopathological analysis revealed transmural inflammation with a large number of noncaseating granulomas (Fig. 6). The patient was therefore given a definitive diagnosis of ileitis-type CD. Since January 2013, she has received treatment with infliximab (IFX, 5 $\mathrm{mg} / \mathrm{kg}$ ) every eight weeks and subsequently maintained a status of clinical remission. 
A

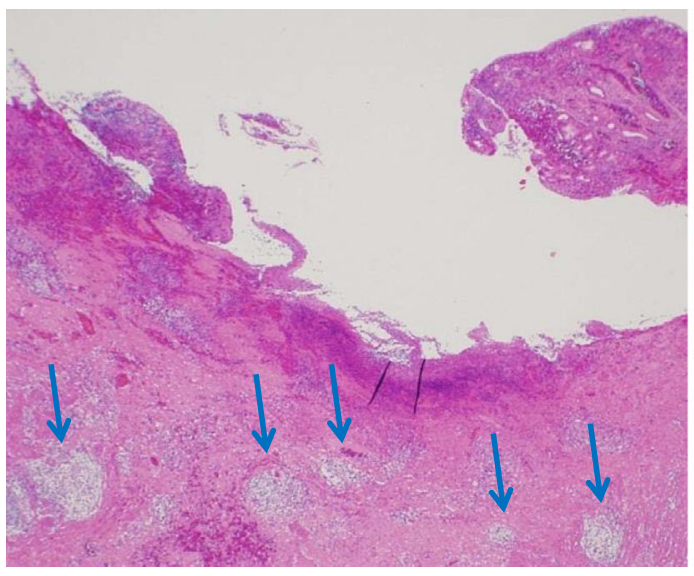

B

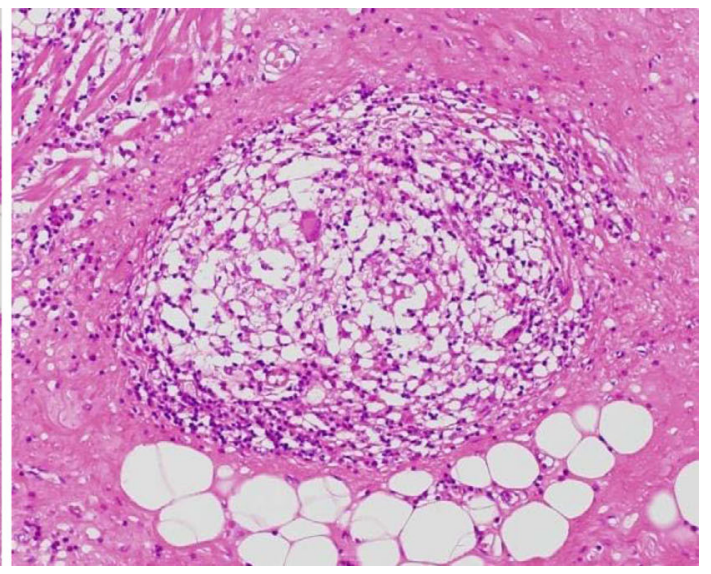

Figure 6. The histopathological analysis revealed transmural inflammation and a large number of non-caseating (epithelioid cells) granulomas (arrows) [A: Hematoxylin and Eosin $(H \& E)$ staining $\times 2$, B: $H \& E$ staining $\times 10]$.

\section{Discussion}

In the past, it was thought that IBD does not recur after OLT due to the continuous administration of immunosuppressive agents. However, several reports have shown that IBD can recur or newly develop (de novo) after OLT. The cumulative risk of recurrent IBD and de novo IBD 10 years after OLT is estimated to be as high as $70 \%$ and $30 \%$, respectively, and the median time between OLT and recurrence/incidence is $1.3 / 5.2$ years (9). In addition, the incidence of de novo IBD after OLT has been shown to be higher than that observed in the general population (206 vs. 20 per 100,000 cases annually) $(2,10)$. There are 92 previous cases of de novo IBD reported in the literature, with the majority of patients having UC (69 UC, 14 CD and others) (Table). This phenomenon may be associated with the fact that most patients with PSC, a common indication for liver transplantation, also have UC (2). However, the development of de novo CD after OLT is rare, and the current article is the first report of such a case in Japan.

Risk factors for and the prognosis of de novo and recurrent IBD have been reported. For example, the use of tacrolimus and presence of CMV infection after OLT have been identified to be risk factors for the onset of de novo and recurrent $\operatorname{IBD}(2,7,9,11-13)$. As for tacrolimus, Haagsma et al. reported six patients who developed de novo IBD; five of whom had been treated with tacrolimus (7). Another study reported that the use of tacrolimus increases the risk of de novo IBD, although not significantly (9). Tacrolimus, a calcineurin inhibitor, strongly inhibits the production of interleukin-2 (IL-2) (7). IL-2 is required for the development of regulatory $\mathrm{T}$ cells (Tregs), which are crucial for maintaining immunological homeostasis in the intestines $(14,15)$. In fact, IL-2-deficient mice spontaneously develop colitis with a normal gut flora $(16,17)$. Therefore, a too strong degree of inhibition of IL-2 by tacrolimus may cause a decrease in the Treg concentration, which may result in the development of UC and/or CD. On the other hand, the efficacy of tacrolimus in UC and CD patients has been reported in several studies (18-20); there are currently no published reports explaining this discrepancy. Cyclosporin A (CyA), which was used in the present case, is also a calcineurin inhibitor. Although the pharmacokinetics of CyA resemble those of tacrolimus, the IL-2 suppressant effects of CyA are weaker than those of tacrolimus, and no previous reports have indicated that CyA is a potential risk factor for de novo IBD (21). In contrast to tacrolimus, the administration of azathioprine after OLT has been reported to reduce the risk of both recurrent and de novo IBD $(7,12)$. Hence, it may be better to use immunosuppressive regimens that include azathioprine, not tacrolimus, in patients with known IBD.

With respect to CMV infection, Verdonk et al. reported that, in their series, all patients who developed de novo IBD after OLT had a history of CMV infection, and no patients who had not experienced CMV infection developed de novo IBD (22). Increased intestinal permeability and endothelialitis may explain the subsequent increased risk for IBD in patients with CMV infection. For example, increased intestinal permeability has been shown to occur during CMV infection in both humans and mouse models $(23,24)$. This defect in the barrier function facilitates the exposure of the mucosal immune system to antigens from the luminal flora (23). In addition, the expression of vascular cell adhesion molecule-1 is induced in endothelial cells under conditions of CMV infection (25-27), which subsequently facilitates the adhesion of leukocytes to the endothelial lining and may play a role in the pathogenesis of endothelialitis. Consequently, endothelialitis may induce damage to the microcirculation of the intestines, thus leading to the development of ulceration and/ or erosion seen in cases of IBD. The present patient did not receive tacrolimus, although she experienced an episode of positive CMV antigenemia after the OLT procedure in 2003. Furthermore, she displayed no symptoms, including enteri- 
tis. However, increased intestinal permeability may occur in cases of asymptomatic CMV infection (25). By the same mechanism, the positive CMV antigenemia noted in this case may have been associated with the onset of de novo CD.

There are various reports regarding the disease course and prognosis of recurrent IBD after OLT. For example, Gavaler et al. reported that $15 / 17(82.4 \%)$ patients with symptomatic UC before OLT experienced an improvement in symptoms after undergoing OLT (28). On the other hand, Verdonk et al. reported that $32 / 49(65 \%)$ patients previously diagnosed with IBD developed recurrence of IBD, and 19/32 (59\%) patients required either dose escalation of medications or colectomy after OLT (9). As to the course and prognosis of de novo IBD, it has been reported that most such cases respond favorably to medical treatment and do not require surgery. According to the literature, $37 / 49$ individuals with de novo IBD achieved remission (Table). The present patient did require surgery; however, remission has been maintained with IFX.

In summary, we herein reported a case of de novo $\mathrm{CD}$ after OLT for congenital biliary atresia despite the continuous use of CyA. To our knowledge, this is the first case report of this condition in Japan. The number of OLT cases in Japan is one-tenth of that observed in Western countries (500/ year vs. 5,000/year). If the number of OLT procedures increases due to the use of organs from brain-dead donors, the incidence of de novo IBD after OLT may increase. The details of the present case suggest that it is important to consider the possibility of de novo IBD in patients who develop refractory diarrhea after OLT, especially those with a history of tacrolimus treatment or CMV infection.

The authors state that they have no Conflict of Interest (COI).

\section{Acknowledgement}

We would like to thank Dr. Mika Watanabe (Division of Pathology, Tohoku University) for assessing the histology slides.

\section{References}

1. Podolsky DK. Inflammatory bowel disease. N Engl J Med 347: 417-429, 2002.

2. Hampton DD, Poleski MH, Onken JE. Inflammatory bowel disease following solid organ transplantation. Clin Immunol 128: 287-293, 2008.

3. Papatheodoridis GV, Hamilton M, Mistry PK, Davidson B, Rolles $\mathrm{K}$, Burroughs AK. Ulcerative colitis has an aggressive course after orthotopic liver transplantation for primary sclerosing cholangitis. Gut 43: 639-644, 1998.

4. Wiesner RH, LaRusso NF. Clinicopathologic features of the syndrome of primary sclerosing cholangitis. Gastroenterology 79: 200-206, 1980.

5. Riley TR, Schoen RE, Lee RG, Rakela J. A case series of transplant recipients who despite immunosuppression developed inflammatory bowel disease. Am J Gastroenterol 92: 279-282, 1997.

6. Vu F, Maillard M, Pascual M, Michetti P, Felley C. [De novo inflammatory bowel diseases after liver transplantation: description of four new cases and a review of the literature]. Gastroenterol
Clin Biol 30: 1096-1101, 2006 (in French).

7. Haagsma EB, Van Den Berg AP, Kleibeuker JH, Slooff MJ, Dijkstra G. Inflammatory bowel disease after liver transplantation: the effect of different immunosuppressive regimens. Aliment Pharmacol Ther 18: 33-44, 2003.

8. Ramji A, Owen DA, Erb SR, Scudamore CH, Yoshida EM. Postliver transplant Crohn's disease: graft tolerance but not selftolerance? Dig Dis Sci 47: 522-527, 2002.

9. Verdonk RC, Dijkstra G, Haagsma EB, et al. Inflammatory bowel disease after liver transplantation: risk factors for recurrence and de novo disease. Am J Transplant 6: 1422-1429, 2006.

10. Venkatesh PG, Navaneethan U, Shen B. Hepatobiliary disorders and complications of inflammatory bowel disease. J Dig Dis 12: 245-256, 2011.

11. Nepal S, Navaneethan U, Bennett AE, Shen B. De novo inflammatory bowel disease and its mimics after organ transplantation. Inflamm Bowel Dis 19: 1518-1527, 2013.

12. Verdonk RC, Haagsma EB, Kleibeuker JH, Dijkstra G, Sudan DL. Cytomegalovirus infection increases the risk for inflammatory bowel disease. Am J Pathol 176: 3098, 2010.

13. Barritt AS 4th, Zacks SL, Rubinas TC, Herfarth HH. Oral budesonide for the therapy of post-liver transplant de novo inflammatory bowel disease: a case series and systematic review of the literature. Inflamm Bowel Dis 14: 1695-1700, 2008.

14. Mahmud SA, Manlove LS, Farrar MA. Interleukin-2 and STAT5 in regulatory $\mathrm{T}$ cell development and function. JAKSTAT 2: e23154, 2013.

15. Coombes JL, Robinson NJ, Maloy KJ, Uhlig HH, Powrie F. Regulatory $\mathrm{T}$ cells and intestinal homeostasis. Immunol Rev 204: 184-194, 2005.

16. Sakaguchi S, Wing K, Miyara M. Regulatory T cells - a brief history and perspective. Eur J Immunol 37 (Suppl 1): S116-S123, 2007.

17. Sadlack B, Merz H, Schorle H, Schimpl A, Feller AC, Horak I. Ulcerative colitis-like disease in mice with a disrupted interleukin2 gene. Cell 75: 253-261, 1993.

18. Ogata $H$, Matsui $T$, Nakamura $M$, et al. A randomised dose finding study of oral tacrolimus (FK506) therapy in refractory ulcerative colitis. Gut 55: 1255-1262, 2006.

19. Thin LW, Murray K, Lawrance IC. Oral tacrolimus for the treatment of refractory inflammatory bowel disease in the biologic era. Inflamm Bowel Dis 19: 1490-1498, 2013.

20. Tamaki H, Nakase H, Matsuura M, et al. The effect of tacrolimus (FK-506) on Japanese patients with refractory Crohn's disease. J Gastroenterol 43: 774-779, 2008.

21. Rostaing L, Puyoo O, Tkaczuk J, et al. Differences in Type 1 and Type 2 intracytoplasmic cytokines, detected by flow cytometry, according to immunosuppression (cyclosporine A vs. tacrolimus) in stable renal allograft recipients. Clin Transplant 13: 400-409, 1999.

22. Verdonk RC, Haagsma EB, Van Den Berg AP, et al. Inflammatory bowel disease after liver transplantation: a role for cytomegalovirus infection. Scand J Gastroenterol 41: 205-211, 2006.

23. Onyeagocha C, Hossain MS, Kumar A, Jones RM, Roback J, Gewirtz AT. Latent cytomegalovirus infection exacerbates experimental colitis. Am J Pathol 175: 2034-2042, 2009.

24. de Maar EF, Kleibeuker JH, Boersma-van Ek W, The TH, van Son WJ. Increased intestinal permeability during cytomegalovirus infection in renal transplant recipients. Transpl Int 9: 576-580, 1996.

25. Bentz GL, Jarquin-Pardo M, Chan G, Smith MS, Sinzger C, Yurochko AD. Human cytomegalovirus (HCMV) infection of endothelial cells promotes naive monocyte extravasation and transfer of productive virus to enhance hematogenous dissemination of HCMV. J Virol 80: 11539-11555, 2006.

26. Koskinen PK, Lemstrom KB, Nieminen MS, Hayry PJ, Lau- 
tenschlager IT. Vascular cell adhesion molecule-1 (VCAM-1) is induced during cytomegalovirus infection in vascular structures of heart allografts. Transpl Int 7 (Suppl 1): S363-S364, 1994.

27. Lautenschlager I, Halme L, Hockerstedt K, Krogerus L, Taskinen E. Cytomegalovirus infection of the liver transplant: virological, histological, immunological, and clinical observations. Transpl Infect Dis 8: 21-30, 2006.

28. Gavaler JS, Delemos B, Belle SH, et al. Ulcerative colitis disease activity as subjectively assessed by patient-completed questionnaires following orthotopic liver transplantation for sclerosing cholangitis. Dig Dis Sci 36: 321-328, 1991.

29. Shaked A, Colonna JO, Goldstein L, Busuttil RW. The interrelation between sclerosing cholangitis and ulcerative colitis in patients undergoing liver transplantation. Ann Surg 215: 598-603; discussion 4-5, 1992.

30. Cuoco L, Tursi A, Cammarota G, Papa A, Fedeli G, Gasbarrini G. Onset of ulcerative colitis during immunosuppressive therapy for liver transplantation. Am J Gastroenterol 92: 2134-2135, 1997.

31. Befeler AS, Lissoos TW, Schiano TD, et al. Clinical course and management of inflammatory bowel disease after liver transplantation. Transplantation 65: 393-396, 1998.

32. Chalasani N, Smallwood G. Idiopathic ulcerative colitis in patients with primary sclerosing colitis undergoing orthotopic liver transplantation (OLT). Am J Gastroenterol 93: 481-482, 1998.

33. Khan S, Lichtman SN, Reyes J, Di Lorenzo C. Ulcerative colitis after liver transplant and immunosuppression. J Pediatr Gastroenterol Nutr 28: 206-209, 1999.

34. Safadi R, Ilan Y, Galun E, et al. Primary sclerosing cholangitis and liver transplantation. Transplant Proc 31: 1896, 1999.

35. Wong NA, Bathgate AJ, Bellamy CO. Colorectal disease in liver allograft recipients -- a clinicopathological study with follow-up. Eur J Gastroenterol Hepatol 14: 231-236, 2002.

36. van de Vrie W, de Man RA, van Buuren HR, Schouten WR, Tilanus HW, Metselaar HJ. Inflammatory bowel disease and liver transplantation for primary sclerosing cholangitis. Eur J Gastroenterol Hepatol 15: 657-663, 2003.

37. Papadakis KA, Matuk R, Abreu MT, et al. Crohn's ileitis after liver transplantation from a living related donor with Crohn's disease. Gut 53: 1389-1390, 2004.

38. Ho GT, Seddon AJ, Therapondos G, Satsangi J, Hayes PC. The clinical course of ulcerative colitis after orthotopic liver transplantation for primary sclerosing cholangitis: further appraisal of immunosuppression post transplantation. Eur J Gastroenterol Hepatol 17: 1379-1385, 2005.

39. MacLean AR, Lilly L, Cohen Z, O'Connor B, McLeod RS. Outcome of patients undergoing liver transplantation for primary sclerosing cholangitis. Dis Colon Rectum 46: 1124-1128, 2003.

40. Worns MA, Lohse AW, Neurath MF, et al. Five cases of de novo inflammatory bowel disease after orthotopic liver transplantation. Am J Gastroenterol 101: 1931-1937, 2006.

41. Cholongitas E, Papatheodoridis GV, Zappoli P, et al. Combined HLA-DR and -DQ disparity is associated with a stable course of ulcerative colitis after liver transplantation for primary sclerosing cholangitis. Liver Transpl 13: 552-557, 2007.

42. Dehghani SM, Eshraghian A, Bahador A, Kakaei F, Geramizadeh B, Malek-Hosseini SA. De novo inflammatory bowel disease after pediatric orthotopic liver transplant: a case report. Exp Clin Transplant 7: 145-148, 2009.

43. Sakamoto T, Sato Y, Yamamoto S, Oya H, Hatakeyama K. De novo ulcerative colitis and autoimmune hepatitis after living related liver transplantation from cytomegalovirus-positive donor to cytomegalovirus-negative recipient: a case report. Transplant Proc 44: 570-573, 2012.

44. Jørgensen KK, Lindstrom L, Cvancarova M, Schrumpf E, Vatn MH, Boberg KM. Clinical course of inflammatory bowel disease in liver transplanted PSC patients: a Nordic multicenter study. Gastroenterology 142: S-7-S-8, 2012.

45. Sandhu A, Alameel T, Dale CH, Levstik M, Chande N. The safety and efficacy of antitumour necrosis factor-alpha therapy for inflammatory bowel disease in patients post liver transplantation: a case series. Aliment Pharmacol Ther 36: 159-165, 2012.

46. Joshi D, Bjarnason I, Belgaumkar A, et al. The impact of inflammatory bowel disease post-liver transplantation for primary sclerosing cholangitis. Liver Int 33: 53-61, 2013.

(C) 2015 The Japanese Society of Internal Medicine http://www.naika.or.jp/imonline/index.html 